\title{
Gastrointestinal Tract Disorder in Natriuretic Peptide Receptor B Gene Mutant Mice
}

\author{
Chizuru Sogawa, ${ }^{* \dagger}$ Asaki Abe, ${ }^{\ddagger}$ Takehito Tsuji, ${ }^{*}$ \\ Mitsuru Koizumi, ${ }^{\dagger}$ Tsuneo Saga $^{\dagger}$ \\ and Tetsuo Kunieda* \\ From the Departments of Animal Genetics, ${ }^{*}$ and Animal \\ Physiology and Pharmacology, Graduate School of Natural \\ Science and Technology, Okayama University, Okayama; and \\ the Diagnostic Imaging Group, ${ }^{\dagger}$ Molecular Imaging Center, \\ National Institute of Radiological Science, Anagawa, Chiba, \\ Japan
}

Natriuretic peptide receptor B (NPR-B), which has high affinity for C-type natriuretic peptide (CNP) and synthesizes intracellular cGMP, may be involved in gastrointestinal tract (GIT) regulation. A mutant allele of the NPR-B-encoding gene (Npr2) is responsible for the phenotype of the short-limb dwarfism (SLW) mouse. Homozygosity for this autosomal-recessive gene $(s h w / s h w)$ leads to dwarfism and death before weaning because of milk retention in the stomach and intestinal distention. To elucidate the relationship between CNP/NPR-B signaling and GIT function, we investigated the association between $N p r 2$ mutation and the GIT phenotype in slw/slw mice. The pylorus and large intestine of the mutants did not respond to CNP stimulation; further, they showed pyloric lumen narrowing with randomly aligned circular muscle cells. Comparison of the cGMP and neuronal marker distribution in GIT tissues confirmed cGMP expression in neuronal tissues. An Auerbach's plexus and submucosal tissues of the mutants didn't express cGMP and expressed $\mathrm{Ca}^{2+}$. In contrast, those of normal mice (controls) expressed both cGMP and $\mathrm{Ca}^{2+}$. Sequencing revealed that the causative $\mathrm{Npr} 2$ mutation was a 7-base deletion in exon 8 , resulting in a frameshift and premature termination codon appearance. Therefore, the GIT phenotype of slw/ slw mice is because of a CNP/NPR-B-signaling defect caused by an Npr2 mutation. These results facilitate better understanding of the role of CNP/NPR-B signaling in GIT motility. (Am J Pathol 2010, 177:822-828; DOI: 10.2353/ajpath.2010.091278)
The natriuretic peptide family comprises atrial natriuretic peptide (ANP), ${ }^{1}$ brain natriuretic peptide (BNP), ${ }^{2}$ and C-type natriuretic peptide (CNP). ${ }^{3}$ There are three known natriuretic peptide receptors (NPRs): type A (NPR-A), type B (NPR-B), and type C (NPR-C). NPR-A and NPR-B consist of extracellular ligand-binding domains, intercellular transmembrane domains, protein kinase homology domains, and the guanylyl cyclase domain; these receptors mediate ligand signals produced by intracellular cyclic guanosine monophosphate (cGMP), which acts as a secondary messenger. ${ }^{4}$ NPR-A preferentially binds ANP and BNP, but it has low affinity for CNP. ${ }^{5}$ NPR-B has higher affinity for CNP than for ANP or BNP. ${ }^{6}$ NPR-C is devoid of intercellular domains; it is believed to be a clearance receptor. ${ }^{5}$

ANP and BNP are circulating peptides synthesized mainly in the atria and ventricles of the heart, respectively. ${ }^{7}$ CNP is present mainly in the vascular endothelium and exhibits different local autocrine and paracrine functions both within and outside the cardiovascular system. ${ }^{8,9}$ These functions are involved in the relaxation of vascular smooth muscles and regulation of cell proliferation and migration. Several studies using mouse models demonstrated that endothelial CNP locally modulates vascular regeneration. ${ }^{10-12}$ Consequently, it was thought that CNP/NPR-B signaling has a similar action on gastrointestinal tract (GIT) relaxation. This hypothesis has been experimentally proved in several animal species, such as rabbits (colon), ${ }^{13}$ guinea pigs (gastric smooth muscle ${ }^{14}$ and coecal smooth muscle), ${ }^{15}$ rats (gastric smooth muscle), ${ }^{16}$ and humans (gastric smooth muscle ${ }^{14}$ and colonic myofibroblasts). ${ }^{17}$ Moreover, the exocrine activity of NPR-B is reportedly localized to the epithelial and muscle cells of the entire GIT in rats, ${ }^{16}$ and NPR-B is believed to play an important role in GIT regulation. However, the

Supported by Department of Animal Genetics, Graduate School of Natural Science and Technology, Okayama University and Diagnostic Imaging Group, Molecular Imaging Center, National Institute of Radiological Sciences, Japan

Accepted for publication April 23, 2010.

Address reprint requests to Chizuru Sogawa, M.Sc., Diagnostic Imaging Group, Molecular Imaging Center, National Institute of Radiological Science 4-9-1 Anagawa, Inage-ku, Chiba 263-8555, Japan. E-mail: c-sogawa@ nirs.go.jp. 
cause-and-effect relationship between CNP/NPR-B signaling and GIT function has not been conclusively demonstrated.

We previously reported about the short-limb dwarfism (SLW) mouse, a mutant strain with an autosomal-recessive gene $(s / W)$ that arose spontaneously in the ddY mouse colony maintained at Okayama University. Mice homozygous for this gene ( $s / w / s / w)$ exhibit disproportionate dwarfism, with short limbs and tail, because of disturbed chondrogenesis during endochondral ossification, caused by a mutation of the gene encoding NPR-B (Npr2) ${ }^{18}$ These mice die before weaning because of milk retention in the stomach and distension of the intestinal tract. This GIT phenotype may be associated with an Npr2 mutation. Therefore, the SLW mouse is an excellent model for investigating the molecular mechanisms of CNP/NPR-B signaling underlying the biological function and motility of the GIT, and identification of the Npr2

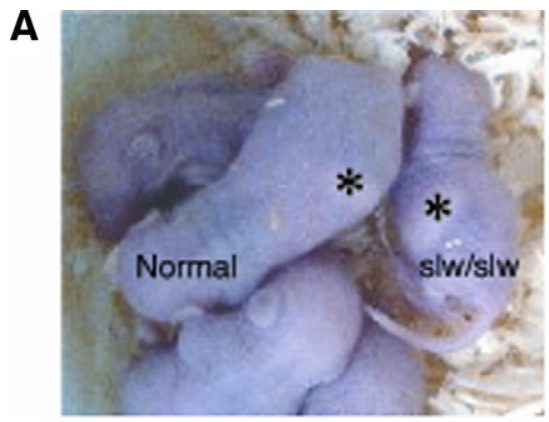

B

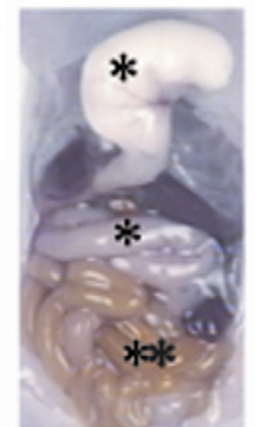

Normal

C

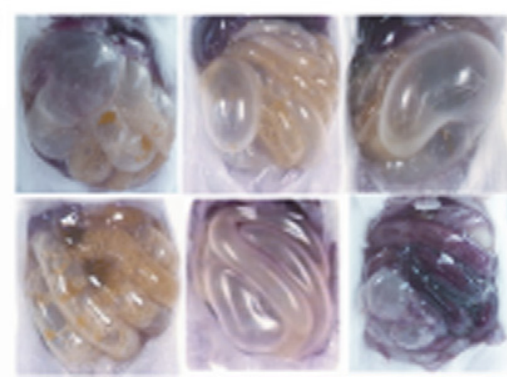

Figure 1. A: Phenotype of SLW mice and their normal littermates at postnatal day five. The slw/slw mouse shows dwarfism and stomach distention. The asterisks indicate milk in the stomach. B: Autopsy results of the GI tract of normal mice and their slw/slw littermates at postnatal day ten. The lower level of the esophagus was cut, and the stomach was removed. The stomach of the $s l w / s l w$ mouse is slightly larger than that of the normal mouse; milk did not enter the intestine, which is dilated and filled with gas. The asterisks indicate milk in the stomach and small intestine, and the double asterisk indicates meconium. C: The autopsied GI tract samples of $s l w / s l w$ mice show that the intestinal tract was distended and filled with gas. mutation responsible for this strain might provide new insight into the genes involved in the processes and functional interaction between gene mutation and phenotypic abnormality. In this study, we examined the GIT phenotype of $s / W / s / W$ mice and investigated the association between CNP/NPR-B signaling and GIT disorders in these mice.

\section{Materials and Methods}

\section{Mice}

An SLW founder male mouse that arose spontaneously in the ddY mouse colony maintained at Okayama University was initially crossed with C57BL/6J female mice to produce $F_{1}$ mice. To establish an inbred strain, sisterbrother mating between heterozygous mice was started from the $F_{1}$ mice. The progeny obtained was used for the experiments. Normal littermates were used as controls. All animal experiments were conducted in accordance with the institutional guidelines for animal care and handling.

\section{Pharmacological Response Study}

A pharmacological response study of the GIT was performed by using a Magnus system connected to a ten-
A

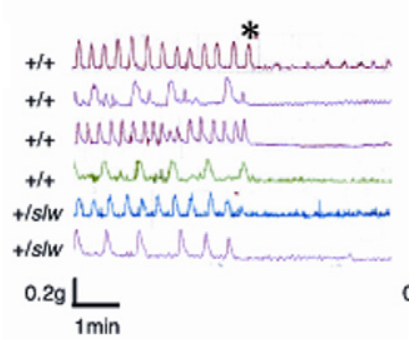

B

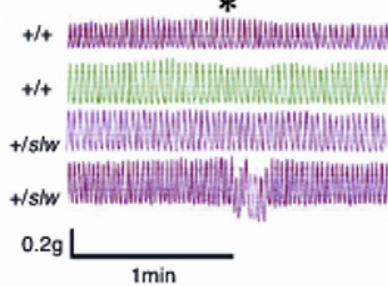

C

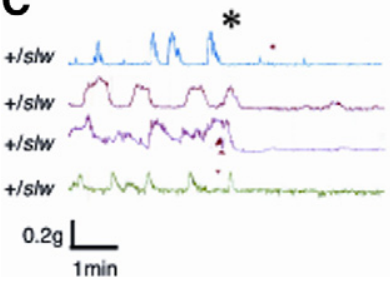

slw/slw

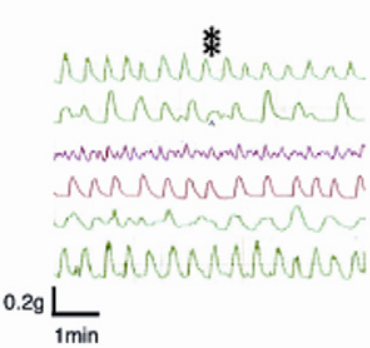

*

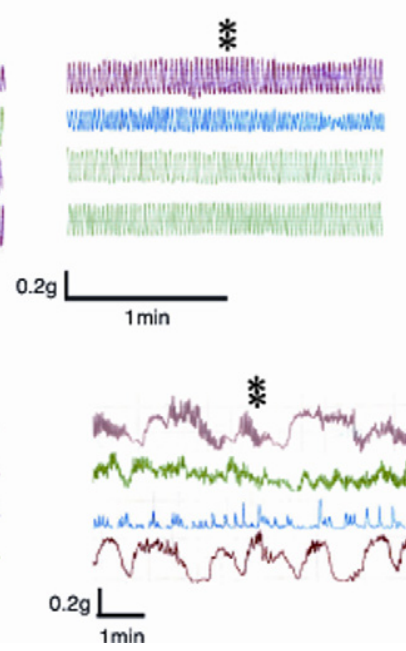

Figure 2. Results of the pharmacological response study of contractility and relaxation by the addition of CNP. Spontaneous contractile activity profile curves of the pylorus (A), small intestine (B), and large intestine (C) of normal and $s l w / s l w$ mice $(n=4-6$ each) are shown. The asterisks and double asterisks indicate the time points at which $10^{-7} \mathrm{~mol} / \mathrm{L} \mathrm{CNP}$ and $10^{-6} \mathrm{~mol} / \mathrm{L} \mathrm{CNP}$, respectively, were added. 
sion converter (Minebea Co. Ltd., Nagano, Japan) and a recorder (Yokogawa Electric Corp., Tokyo, Japan). ${ }^{19}$

Normal and s/w/s/w mice were sacrificed under anesthesia at postnatal days 14-17, and their pylorus, jejunum, and large intestine were collected and placed in physiological salt solution (PSS) containing $136.9 \mathrm{mmol} / \mathrm{L}$ $\mathrm{NaCl}, 5.4 \mathrm{mmol} / \mathrm{L} \mathrm{KCl}, 23.8 \mathrm{mmol} / \mathrm{L} \mathrm{NaHCO}_{3}, 5.5 \mathrm{mmol} / \mathrm{L}$ glucose, $1.5 \mathrm{mmol} / \mathrm{L} \mathrm{CaCl}_{2}, 1.0 \mathrm{mmol} / \mathrm{L} \mathrm{MgCl}_{2}$, and 0.01 $\mathrm{mmol} / \mathrm{L}$ ethylenediaminetetraacetic acid (EDTA). Then, approximately 5-mm-long tissue strips were sectioned and resuspended in $10 \mathrm{ml}$ of fresh PSS at $37^{\circ} \mathrm{C}$ in an atmosphere containing $95 \% \mathrm{O}_{2}$ and $5 \% \mathrm{CO}_{2}$. Subsequently, CNP-22 (Peptide Institute Inc., Osaka, Japan) was added to the PSS solution to reach a final concentration of $10^{-7} \mathrm{~mol} / \mathrm{L}$ or $10^{-6} \mathrm{~mol} / \mathrm{L}$. Contractile and relaxant movement profiles were recorded.

\section{Histology and Immunostaining}

Normal and s/w/s/w mice were sacrificed under anesthesia at postnatal days 10-20, and their GIT was prepared from the stomach to the anus. The entire GIT was fixed overnight in Bouin's solution containing $75 \mathrm{ml}$ of saturated picric acid, $25 \mathrm{ml}$ of $37 \%$ formaldehyde, and $5 \mathrm{ml}$ of glacial acetic acid at room temperature. The pylorus, small intestine, and large intestine were then separated. The specimens were dehydrated and embedded in paraffin. Sections of $4-\mu \mathrm{m}$ thickness were cut and stained with hematoxylin and eosin (H\&E).

We investigated cGMP expression and neuronal distribution by immunohistochemical analysis. The GIT was prepared from the stomach to the anus and fixed overnight in Bouin's solution at room temperature. The specimens were dehydrated and embedded in paraffin. Sections of $4-\mu \mathrm{m}$ thickness were cut, attached to a slide glass, deparaffinized, and incubated in sodium citrate buffer containing $10 \mathrm{mmol} / \mathrm{L}$ sodium citrate $(\mathrm{pH}$ 6.0) and $0.05 \%$ Tween-20 for 20 minutes at $95^{\circ} \mathrm{C}$ for antigen retrieval. The sections were washed in distilled water and then immersed in Tris-buffered saline (TBS) (DAKO S3001; DAKO Japan, Tokyo, Japan) for 5 minutes, followed by incubation with peroxidase blocking solution
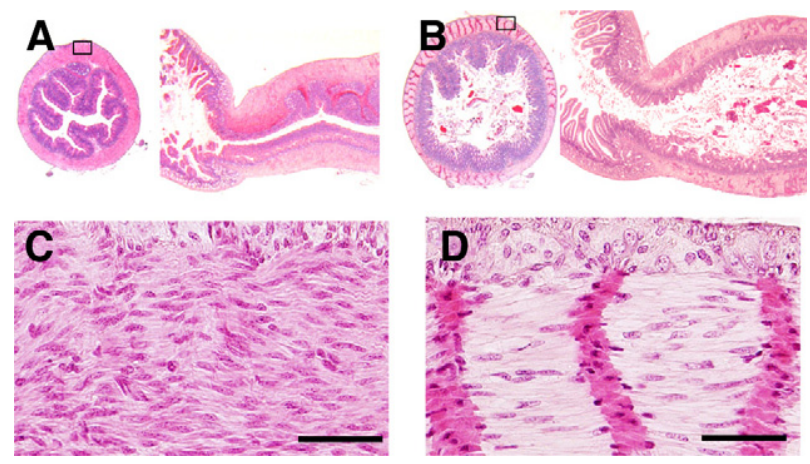

Figure 3. Results of the histological analysis (H\&E staining) of slw/slw mice (A and $\mathbf{C}$ ) and their normal littermates (B and $\mathbf{D})$ at postnatal day 20. $\mathbf{A}$ and B: Axial (left) and sagittal (right) sections of the pylorus. C and D: Higher magnification images of the boxed areas in $\mathbf{A}$ and $\mathbf{B}$, respectively. Scale bars $=50 \mu \mathrm{m}$.
( $3 \% \mathrm{H}_{2} \mathrm{O}_{2}$ in methanol) at room temperature for $10 \mathrm{~min}$ utes. Each section was washed thrice for 5 minutes with TBS and incubated with a nonspecific blocking reagent $(0.25 \%$ casein in phosphate-buffered saline containing stabilizing protein, DAKO X0909; DAKO Japan) for 10 minutes at room temperature. The reaction with the primary antibodies was performed for 1 hour at room temperature. Three kinds of primary antibodies (all sourced from Abcam KK, Tokyo, Japan) were used: PDE5A, specific to cGMP phosphodiesterase type 5A (rabbit polyclonal ab14672, 1:10 dilution); PGP9.5-Neuronal Marker, specific to neuronal cell bodies and axons in the central and peripheral neuronal systems (mouse monoclonal ab8189, 1:10 dilution); S-100 antibody 4B3, specific to $\mathrm{Ca}^{2+}$ in the cytoplasm and nuclei of astrocytes, Schwann cells, and other cells (mouse monoclonal ab14849, 1:3000 dilution). After the incubation with the primary antibodies, each section was washed thrice for 5 minutes with TBS at room temperature and then incubated with secondary antibody labeled with peroxidase (ENVISION+, mouse HRP or rabbit HRP, DAKO K4000 and K4002; DAKO Japan) for 1 hour at room temperature. The sections were washed in distilled water, stained with diaminobenzidine (DAKO K3465; DAKO Japan) for 2 minutes at room temperature, and washed in distilled water again. Nuclear staining was performed with hematoxylin.

For fluorescent immunostaining, the tissue sections were prepared as for the immunohistochemical study till the blocking of nonspecific binding. Two primary anti-
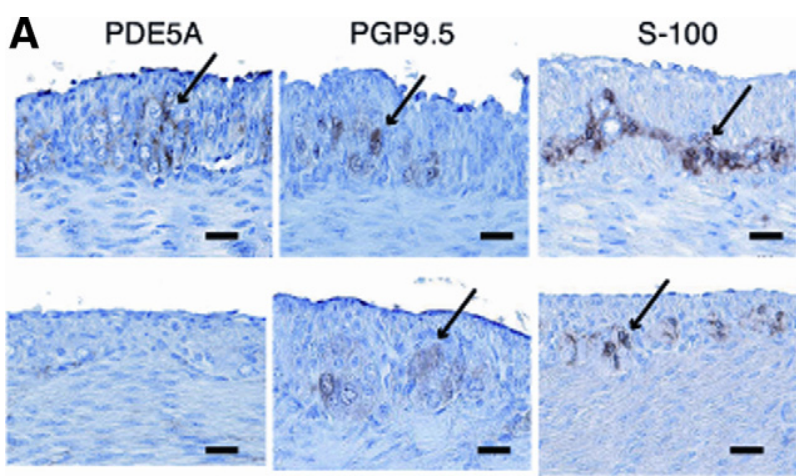

\section{B}

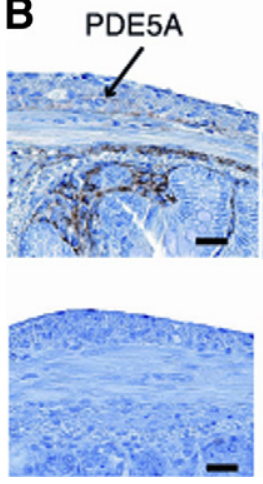

PGP9.5

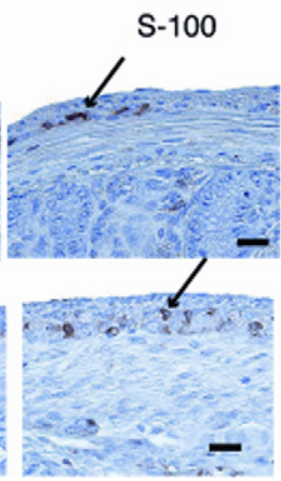

Figure 4. Results of the immunohistochemical analysis of the pylorus (A) and large intestine (B) of normal mice (upper row) and their slw/slw littermates (lower row) by using PDE5A (specific to cGMP phosphodiesterase type 5A) and neuronal markers (PGP9.5 and S-100). Note the difference in cGMP expression in the pylorus and large intestine of the littermates (arrows). These sites were considered to be Auerbach's plexus. Scale bars $=20 \mu \mathrm{m}$. 
bodies were used: PDE5A (diluted to 1:10) and S-100 (diluted to 1:3000) were mixed and reacted for 1 hour at room temperature. Subsequently, each section was washed thrice for 5 minutes with TBS containing 0.05\% Tween-20 (TBS-T) at room temperature. The sections were incubated with two fluorescence-labeled secondary antibody mixtures (goat polyclonal to rabbit IgG-H\&L Cy3, ab6939, 1:50 dilution; goat polyclonal to mouse IgG-H\&L Cy5, ab6563, 1:50 dilution; both sourced from Abcam KK) in a nonspecific blocking solution containing normal goat serum (G9023, 1:10 dilution; Sigma-Aldrich, Japan) for 1 hour at room temperature with light interception. All procedures after the secondary antibody reaction were performed in the dark. Subsequently, each section was washed thrice for 5 minutes with TBS-T at room temperature and then reacted with DAPI-Fluoromount-G (0100-20; Southern Biotech, Birmingham, AL) on mounting slides. The fluorescent images were captured with an Olympus Fluoview FV1000 confocal microscope.

\section{Sequencing}

Total RNA was extracted from the brain of normal and s/W/s/W mice by using TRIzol reagent (Invitrogen, Tokyo, Japan) according to the manufacturer's instructions. cDNA was synthesized from total RNA by using the oligo $d(T)$ primer and Superscript III reverse transcriptase (Invitrogen). The entire coding region of Npr2 was amplified by reverse transcriptase-polymerase chain reaction (RTPCR). The following Npr2-specific primers were used: Npr2-1, F5'-TGTATCCGGGCCGACTAAGCTTGC-3' and R5'-CTACAAACTCACCCAGCTTGG-3'; Npr2-2, R5'AGTGGCCTCTGGCTTTGCAGC-3' and F5'-GCCAGCTCCACACCAAAGT-3'; Npr2-3, F5'-GGTGATCACATACCGAGAACC-3' and R5'-GCACCCTTGTGATAGCGATCCGAG-3'; Npr2-4, F5'-CTAGCATGCTATGGCGCATTCACTG-3' and R5'-AGAAAGGACCACTTCGAAGTGC-3'; Npr2-5, F5'-CCTCAGTCCCAAGGAGATTGTCCAG-3' and R5'-AGGCATCCCCAATGGTTTCCACC-3'; Npr2-6, F5'-TTCACAGCGCTGTCAGCTGAG-3' and R5'-GGAAACACAGTGACCATTGCCCATC-3'. The amplified fragments were sequenced by using an ABI PRISM 310 genetic analyzer (Applied Biosystems Japan Ltd., Tokyo, Japan).
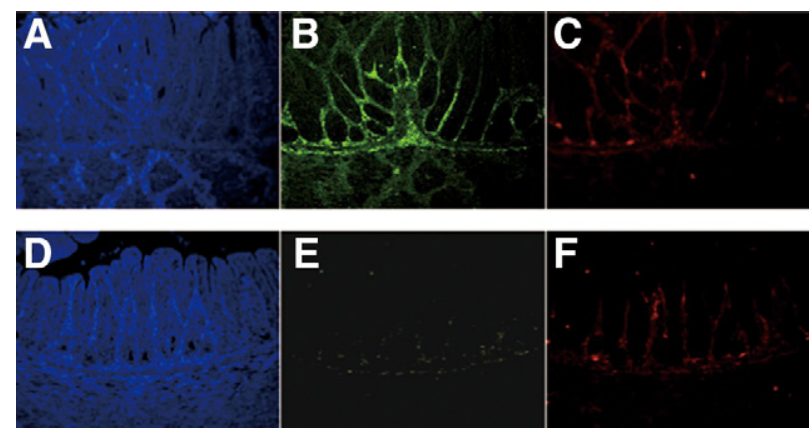

Figure 5. Pyloric samples of normal mice $(\mathbf{A}, \mathbf{B}$, and $\mathbf{C})$ and their $s l w / s l w$ littermates (D, E, and F) were stained with PDE5A (green) and S-100 (red) for immunofluorescence study ( $\times 400$ magnification). Note the inadequate PDE5A staining of the pylorus of the $s l w / s l w$ mice compared with that of the normal mice. The blue staining was achieved with DAPI.
To detect the Npr2 mutation in the s/w/s/w mice, PCR products were obtained using specific primers F5'CTAGCATGCTATGGCGCATTCGCTG-3' and R5'-AGGCGACTGCCTGCACCCTTGTG-3', and electrophoresed on $8 \%$ acrylamide gel.

\section{Results}

\section{Early Death of Mutant Mice}

The $s / w / s / w$ mice exhibited early death, with most individuals showing milk retention in the stomach and distention of the intestinal tract with gas; in contrast, the milk ingested by the normal mice was transported to the small intestine (Figure 1, A and B). Autopsy of the mutant mice confirmed distention of the intestinal tract with gas (Figure 1, B and C); most of these mice died as a result of the intestinal distention before weaning.

\section{Response of the GIT to CNP Stimulation}

Spontaneous contractile movement of the tissue strips from all regions of the GIT of the normal and $s / w / s / w$ mice was recorded. In the pylorus and large intestine of the normal mice, the relaxation response occurred immediately after the addition of $10^{-7} \mathrm{~mol} / \mathrm{L} \mathrm{CNP}$, whereas the s/W/s/W mice did not show a response even at the CNP level of $10^{-6} \mathrm{~mol} / \mathrm{L}$ (Figure 2, A and C). On the other hand, the small intestine of neither type of mouse responded to the $10^{-6} \mathrm{~mol} / \mathrm{L} \mathrm{CNP}$ stimulation (Figure $2 \mathrm{~B}$ ).

\section{Histology and Immunohistochemistry of the GIT}

The histological analysis revealed that the pylorus of the s/W/s/W mice was markedly narrowed (Figure 3A), but such narrowing was not observed in the normal mice (Figure 3B). Pyloric smooth muscle cells of the mutant mice were randomly aligned (Figure $3 \mathrm{C}$ ), whereas those of the normal mice were aligned in one direction (Figure 3D).

Npr2 encodes NPR-B, which produces the intracellular secondary messenger cGMP in response to CNP. Therefore, we examined cGMP expression in the GIT using PDE5A. Immunohistochemistry using neuronal markers
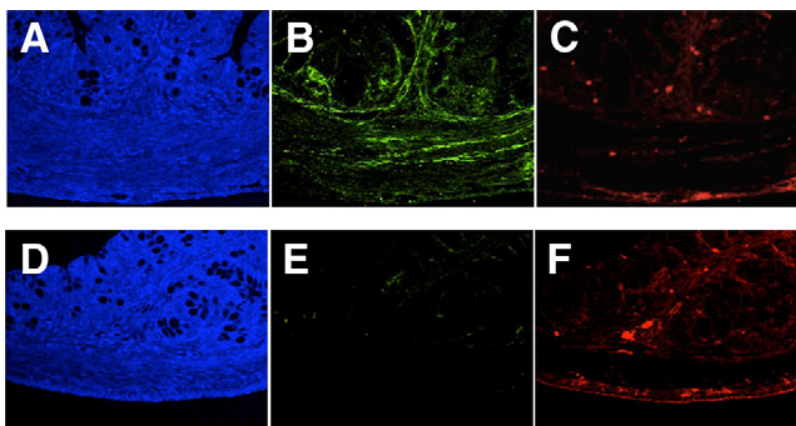

Figure 6. Large intestinal samples of normal mice $(\mathbf{A}, \mathbf{B}$, and $\mathbf{C})$ and their slw/slw littermates (D, E, and $\mathbf{F}$ ) were stained with PDE5A (green) and S-100 (red) for immunofluorescence study ( $\times 400$ magnification). The sample from an $s l w / s l w$ mouse does not show adequate PDE5A staining compared with that of a normal mouse. A and $\mathbf{D}$ (blue) show DAPI staining. 
was performed to exclude the possibility of partial neurogangional defects in s/w/s/w mice. Comparison of the distribution of cGMP and the neuronal markers confirmed that CGMP was expressed in nerve tissues such as Auerbach's plexus and submucosal tissue. The morphology and immunohistochemical pattern of Auerbach's plexus in the pylorus and large intestine of the s/w/s/w mice were not different from those of the normal mice (Figures 3 and $4 A, B)$. These results indicated that the lack of the CNP response in the pylorus and large intestine of the mutant mice was not derived from a deficiency of neuronal tissue but was attributable to the lack of the cGMP signal. Moreover, no morphological difference of the myenteric nerve plexus cells in other parts of the intestine was detectable between the littermates (data not shown).

\section{Localization of CGMP and $\mathrm{Ca}^{2+}$ in the GIT}

Fluorescent immunostaining was performed to confirm the results of immunohistochemistry and investigate the relationship between cGMP and $\mathrm{Ca}^{2+}$ in the GIT. In this experiment, fluorescent immunostaining of two antibodies (PDE5A and S-100) was performed simultaneously for the same tissue section, to compare the distribution of cGMP and $\mathrm{Ca}^{2+}$ directly. In the pylorus (Figure 5, A-F and large intestine (Figure 6, A-F), cGMP expression was intense in the normal mice but absent in the s/w/s/w mice. $\mathrm{Ca}^{2+}$ expression was not different between the littermates. There was no detectable cGMP expression and weak $\mathrm{Ca}^{2+}$ expression in the small intestine of both the normal mice and the mutant mice (Figure 7, A-F). Furthermore, the expression pattern of cGMP was quite similar to that of $\mathrm{Ca}^{2+}$ in the normal mice. The immunofluorescence results not only confirmed the immunohistochemistry results but also showed the similarity of cGMP and $\mathrm{Ca}^{2+}$ distribution in the normal mice.

\section{Identification of Npr2 Mutation}

To identify the causative Npr2 mutation in s/w/s/w mice, we amplified and sequenced the entire coding region of Npr2 and compared this sequence between s/w/s/w mice and wild-type mice. By sequence analysis, a 7-base deletion was identified in exon 8 of $N p r 2$ in the $s / w / s / W$
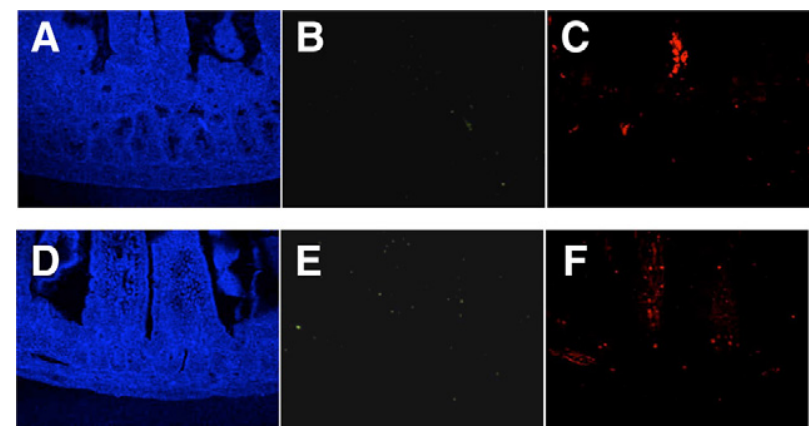

Figure 7. Jejunal samples of normal mice (A, B, and $\mathbf{C})$ and their $s l w / s l w$ littermates (D, E, and F) were stained with PDE5A (green) and S-100 (red) for immunofluorescence study ( $\times 400$ magnification). The samples from both types of mice show lack of PDE5A staining and weak S-100 staining. The blue staining was achieved with DAPI. mice. Exon 8 codes for the domain present just under the transmembrane domain of NPR-B. The deletion caused a frameshift and the appearance of a premature termination codon at codon 513 (Figure 8A). To confirm that the 7-base deletion is unique to the s/w mutant allele, gene fragments including the deletion area in Npr2 exon 8 were amplified in four inbred strains of mice. Consequently, a 75-bp fragment from the s/w/s/w mice and an 82-bp fragment from the wild-type mice and inbred strains were amplified. In addition, 75-bp, 82-bp, and heteroduplex fragments from the heterozygous mice were amplified (Figure 8B). The results indicated that the 7-base deletion in Npr2 was unique to the mutant allele.

\section{Discussion}

This is the first report clarifying the relationships among an Npr2 mutation, physiological and morphological abnormalities of CNP/NPR-B signaling in the GIT, and the GIT phenotype. We have shown that SLW mice exhibit a disorder of the GIT.

The pharmacological response study of the GIT revealed that normal and $s / w / s / w$ mice do not show different spontaneous or baseline contractile movement but exhibit different responses to CNP stimulation. However, the small intestine of both types of mice did not respond to CNP (Figure 2). These results correspond to the cGMP expression pattern (Figures 4-7). Moreover, the GI nerve system of the s/w/s/w mice was shown not to be different from that of their normal littermates, as shown by the morphology and immunohistochemical methods. These results suggest that CNP/NPR-B signaling is essential for site-specific relaxation activity in the GIT. CNP signaling is known to be involved in relaxant activity and the regulation of cell proliferation and differentiation in the vascular endothelium. ${ }^{8-12}$ Therefore, we speculated that CNP signaling has similar effects on the GIT and that the GIT phenotype of $s / w / s / w$ mice is the result of a flaw in the control system of CNP/NPR-B signaling caused by a mutation of Npr2. We speculated that the Npr2 abnormality in $s / w / s / w$ mice causes deletion of the intracellular domain of NPR-B. We have illustrated a putative NPR-B protein in s/w/s/w mice in Figure 9. Fluorescent immunostaining with S-100 antibody (specific to $\mathrm{Ca}^{2+}$ ) showed positive results in the neuronal and submucosal tissues of the pylorus and large intestine of both $s / w / s / w$ mice and normal mice. In these regions, the expression of cGMP was positive in the normal littermates but negative in the s/w/s/w mice. Further, the distribution patterns of cGMP and $\mathrm{Ca}^{2+}$ are quite similar in normal mice. Reportedly, cGMP acts on the calcium channel of the cell membrane and sarcoplasmic reticulum in vascular smooth muscle and regulates $\mathrm{Ca}^{2+}$ exchange in the cell membrane, thereby controlling muscle tension (relaxation and contraction). ${ }^{20-23}$ Moreover, CNP is expressed in various nerve systems, such as the central, sensory, and parasympathetic nerves, and acts as a neurotransmitter. $^{3,24,25}$ We speculate that a similar CNP/NPR-B/CGMP pathway and $\mathrm{Ca}^{2+}$ distribution may exist in the GIT. 
A
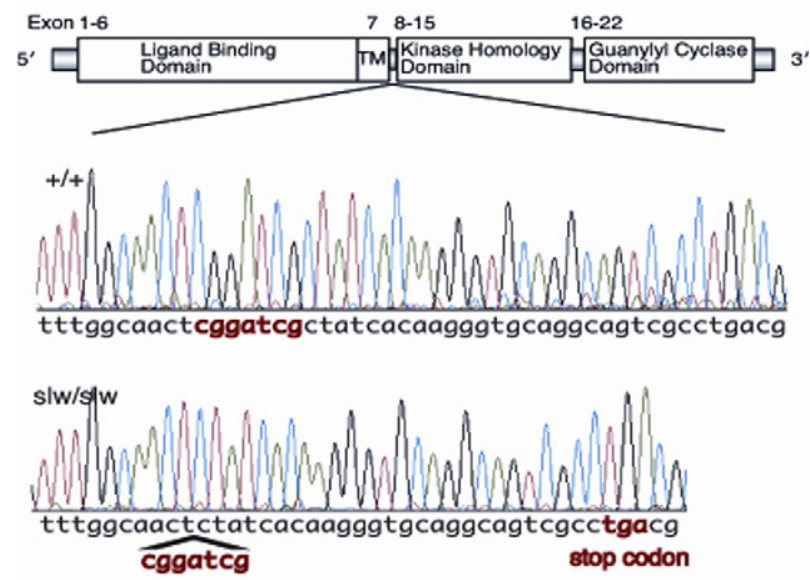

B

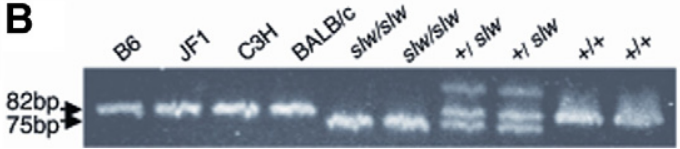

Figure 8. A: Structure of NPR-B and nucleotide sequences of Npr2 in wild-type $(+/+)$ and $s l w / s l w$ mice. A 7 -base deletion was identified in exon 8 of the $s l w / s l w$ mice ("cggatcg" in red). Exon 8 of Npr 2 codes for the domain just below the transmembrane domain of NPR-B. The deletion caused a frameshift and the appearance of a premature termination codon at codon 513 ("tga" in red). B: Detection of an Npr2 mutation by electrophoresis using acrylamide gel. Examination of the amplified PCR fragments including the 7-base deletion in exon 8 confirmed that the deletion was unique to the mutant allele.

CNP-knockout mice reportedly show early death: in a study, more than half of them died before weaning and only $30 \%$ survived till the age of 100 days. ${ }^{26}$ NPR-B-knockout mice had shorter life spans than normal mice, ${ }^{10}$ but they did not show GIT abnormalities. Possibly, their early death and short life span are related to abnormalities in the motility and function of the GIT, as observed in the case of s/w/s/w mice. However, another Npr2 mutant strain, the CN mutant mouse with a missense mutation in Npr2, ${ }^{27}$ did not show any abnormality of the GIT and early death. The differences in the genetic background of mice belonging to different strains or harboring different types of mutation might be responsible for these findings. We believe that the SLW mouse would be a unique tool for analyzing the role of Npr2 in the relaxant action system of the GIT.

Several mutant mice have been reported to exhibit abnormalities of the GIT. c-kit plays a functional role in the development of intestinal pacemaker cells called interstitial cells of Cajal (ICCS). Both c-kit mutant and Kit-ligand mutant mice 28,29 lack the network of ICCs and intestinal pacemaker activity; ${ }^{30}$ as ICCs are not developed in these mice, their enteric tissues show irregular spontaneous contractile activity. Edn3 and Ednrb are also required for the development of enteric neurons. These mutant mice ${ }^{31-33}$ show early death from megacolon caused by enteric neuron defects and their characteristics reportedly mimic human Hirschsprung disease.

The enteric tissue strips of the s/w/s/w mice displayed regular spontaneous contractions, and a myenteric nerve plexus was observed in the GIT. The GIT phenotype of $s / w / s / W$ mice is unique and distinct from that of other

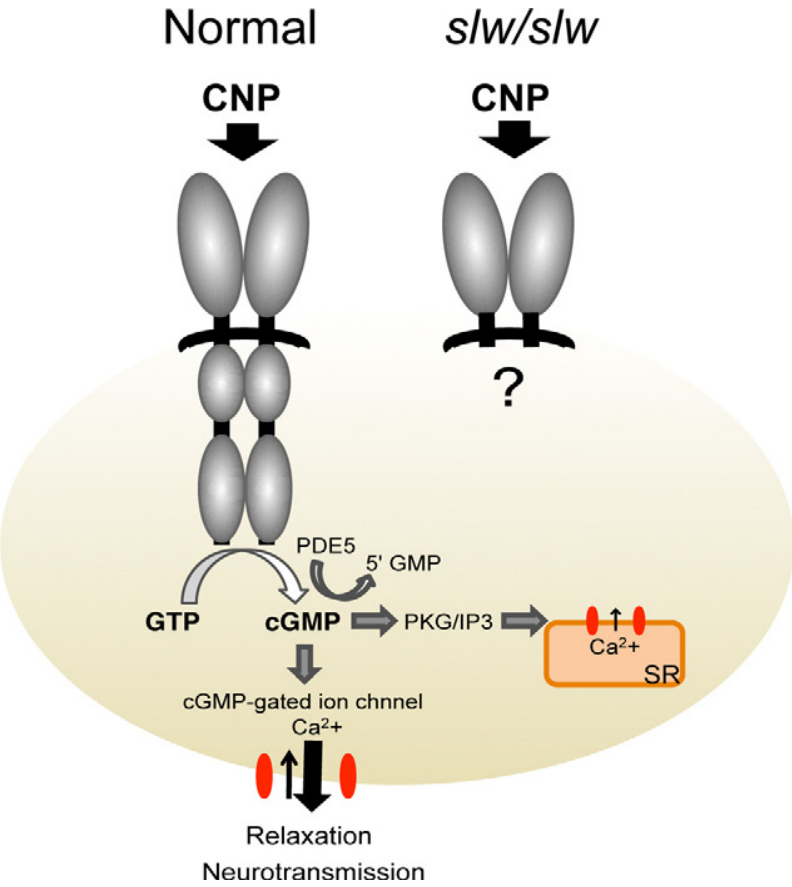

Figure 9. Putative model of the NPR-B structure and signal cascade. In normal mice, CNP signaling results in relaxation of the pylorus and large intestine via cGMP production. In slw/slw mice, the CNP signal does not produce cGMP because of the lack of the intracellular element of NPR-B, resulting in the absence of pyloric and large intestinal relaxation.

mutant mice with GIT abnormalities. NPR-B mediates the relaxation of the pylorus and large intestine; therefore, mutations of Npr2 disrupt this relaxation effect. The s/w/ s/w mouse seems to be a novel type of mutant that exhibits GIT abnormality resembling infantile hypertrophic pyloric stenosis (IHPS) or cystic fibrosis (CF).

IHPS is characterized by severe vomiting and weight loss in the first few months of life. Moreover, pyloric narrowing occurs because of hypertrophy of the surrounding musculature. Neuronal nitric oxide synthase is reportedly involved in the pathogenesis of IHPS. ${ }^{34} \mathrm{Neu}-$ ronal nitric oxide synthase generates nitric oxide, and nitric oxide signaling mediated by soluble guanylyl cyclase produces cGMP. Therefore, it is highly possible that IHPS is induced by the loss of cGMP production, similar to that in $s / w / s / w$ mice, wherein guanylyl cyclase activity affects CNP/NPR-B signaling. In the s/w/s/w mice, with deficient CNP/NPR-B signaling, cGMP expression was reduced or absent and a response to the CNP stimulus was not observed (Figure 2). We therefore consider that CNP plays a pivotal role in GIT motility.

CF is a hereditary disease that affects the exocrine glands of the lung, liver, pancreas, and intestine; it is caused by a mutation in the cystic fibrosis transmembrane conductance regulator (CFTR) gene. Meconium may completely block the intestine in this disease. This ileus is caused by abnormalities of the chloride channel. In the mouse, the genetic defect responsible for CF affects the movement of chloride in and out of cells, and CNP activates CFTR-dependent chloride transport. ${ }^{35}$ Therefore, abnormalities of CNP/NPR-B signaling in s/W/ $s / W$ mice may be associated with the mechanism of these 
diseases. However, these possibilities need to be investigated in humans.

In conclusion, CNP/NPR-B signaling plays a pivotal role in the GIT and GIT nerve system of the mouse. Further studies using s/W/s/W mice and humans will facilitate better understanding of the role of CNP/NPR-B signaling in GIT motility and contribute toward the development of novel therapeutic approaches for diseases such as IHPS and CF.

\section{Acknowledgments}

We thank Dr. Sumitaka Hasegawa (Diagnostic Imaging Group, Molecular Imaging Center, National Institute of Radiological Science) and Tasuku Yamashita (Okayama University) for their helpful discussions and valuable suggestions. We also thank Dr. Yuka Asano (Okayama University) for maintenance of the SLW strain.

\section{References}

1. de Bold AJ: Atrial natriuretic factor: a hormone produced by the heart. Science 1985, 230:767-770

2. Sudoh T, Kangawa K, Minamino N, Matsuo $H$ : A new natriuretic peptide in porcine brain. Nature 1988, 332:78-81

3. Sudoh T, Minamino N, Kangawa K, Matsuo H: C-type natriuretic peptide (CNP): a new member of natriuretic peptide family identified in porcine brain. Biochem Biophys Res Commun 1990, 168:863-870

4. Potter LR, Hunter T: Guanylyl cyclase-linked natriuretic peptide receptors: structure and regulation. J Biol Chem 2001, 276:6057-6060

5. Koller KJ, Goeddel DV: Molecular biology of the natriuretic peptides and their receptors. Circulation 1992, 86:1081-1088

6. Koller KJ, Lowe DG, Bennett GL, Minamino N, Kangawa K, Matsuo H, Goeddel DV: Selective activation of the B natriuretic peptide receptor by C-type natriuretic peptide (CNP). Science 1991, 252:120-123

7. Mukoyama M, Nakao K, Hosoda K, Suga S, Saito Y, Ogawa Y, Shirakami G, Jougasaki M, Obata K, Yasue H: Brain natriuretic peptide as a novel cardiac hormone in humans. Evidence for an exquisite dual natriuretic peptide system, atrial natriuretic peptide and brain natriuretic peptide. J Clin Invest 1991, 87:1402-1412

8. Suga S, Nakao K, Itoh H, Komatsu Y, Ogawa Y, Hama N, Imura H: Endothelial production of $\mathrm{C}$-type natriuretic peptide and its marked augmentation by transforming growth factor-beta: possible existence of "vascular natriuretic peptide system." J Clin Invest 1992, 90:1145-1149

9. Chen $\mathrm{HH}$, Burnett JC Jr: C-type natriuretic peptide: the endothelial component of the natriuretic peptide system. J Cardiovasc Pharmacol 1998, 32 (Suppl 3):S22-S28

10. Tamura N, Doolittle LK, Hammer RE, Shelton JM, Richardson JA, Garbers DL: Critical roles of the guanylyl cyclase B receptor in endochondral ossification and development of female reproductive organs. Proc Natl Acad Sci USA 2004, 101:17300-17305

11. Komatsu Y, Itoh H, Suga S, Ogawa Y, Hama N, Kishimoto I, Nakagawa O, Igaki T, Doi K, Yoshimasa T, Nakao K: Regulation of endothelial production of C-type natriuretic peptide in coculture with vascular smooth muscle cells: role of the vascular natriuretic peptide system in vascular growth inhibition. Circ Res 1996, 78:606-614

12. Yamahara K, Itoh $H$, Chun TH, Ogawa $Y$, Yamashita J, Sawada N, Fukunaga Y, Sone M, Yurugi-Kobayashi T, Miyashita K, Tsujimoto $H$, Kook H, Feil R, Garbers DL, Hofmann F, Nakao K: Significance and therapeutic potential of the natriuretic peptides/cGMP/cGMP-dependent protein kinase pathway in vascular regeneration. Proc Natl Acad Sci USA 2003, 100:3404-3409

13. Kim JH, Jeon GJ, Kim SZ, Cho KW, Kim SH: C-type natriuretic peptide system in rabbit colon. Peptides 2001, 22:2061-2068

14. Guo HS, Jin Z, Jin ZY, Li ZH, Cui YF, Wang ZY, Xu WX: Comparative study in the effect of C-type natriuretic peptide on gastric motility in various animals. World J Gastroenterol 2003, 9:547-552

15. Itaba S, Chijiiwa Y, Matsuzaka H, Motomura $Y$, Nawata $H$ : Presence of C-type natriuretic peptide (CNP) in guinea pig caecum: role and mechanisms of CNP in circular smooth muscle relaxation. Neurogastroenterol Motil 2004, 16:375-382

16. Rambotti MG, Giambanco I, Spreca A: Detection of guanylate cyclases $A$ and $B$ stimulated by natriuretic peptides in gastrointestinal tract of rat. Histochem J 1997, 29:117-126

17. Chitapanarux T, Chen SL, Lee H, Melton AC, Yee HF Jr: C-type natriuretic peptide induces human colonic myofibroblast relaxation. Am J Physiol Gastrointest Liver Physiol 2004, 286:G31-G36

18. Sogawa C, Tsuji T, Shinkai Y, Katayama K, Kunieda T: Short-limbed dwarfism: slw is a new allele of Npr2 causing chondrodysplasia. J Hered 2007, 98:575-580

19. Abe A, Kawasoe C, Kondo Y, Sato K: Enhancement of norepinephrine-induced transient contraction in aortic smooth muscle of diabetic mice. Acta Med Okayama 2003, 57:45-48

20. Berridge MJ: Cell signalling. A tale of two messengers. Nature 1993, 365:388-389

21. Komalavilas P, Lincoln TM: Phosphorylation of the inositol 1,4,5trisphosphate receptor by cyclic GMP-dependent protein kinase. J Biol Chem 1994, 269:8701-8707

22. Ruiz-Velasco V, Zhong J, Hume JR, Keef KD: Modulation of $\mathrm{Ca}^{2+}$ channels by cyclic nucleotide cross activation of opposing protein kinases in rabbit portal vein. Circ Res 1998, 82:557-565

23. Zhao Z, Ma L: Regulation of axonal development by natriuretic peptide hormones. Proc Natl Acad Sci USA 2009, 106:18016-18021

24. Herring N, Zaman JA, Paterson DJ: Natriuretic peptides like NO facilitate cardiac vagal neurotransmission and bradycardia via a cGMP pathway. Am J Physiol Heart Circ Physiol 2001, 281:H2318-H2327

25. Kishimoto I, Tokudome T, Horio T, Soeki T, Chusho H, Nakao K Kangawa $\mathrm{K}$ : C-type natriuretic peptide is a Schwann cell-derived factor for development and function of sensory neurones. J Neuroendocrinol 2008, 20:1213-1223

26. Chusho H, Tamura N, Ogawa Y, Yasoda A, Suda M, Miyazawa T, Nakamura K, Nakao K, Kurihara T, Komatsu Y, Itoh H, Tanaka K, Saito Y, Katsuki M, Nakao K: Dwarfism and early death in mice lacking C-type natriuretic peptide. Proc Natl Acad Sci USA 2001, 98:4016-4021

27. Tsuji T, Kunieda T: A loss-of-function mutation in natriuretic peptide receptor 2 (Npr2) gene is responsible for disproportionate dwarfism in cn/cn mouse. J Biol Chem 2005, 280:14288-14292

28. Geissler EN, Ryan MA, Housman DE: The dominant-white spotting (W) locus of the mouse encodes the c-kit proto-oncogene. Cell 1988, 55:185-192

29. Williams DE, Eisenman J, Baird A, Rauch C, Van Ness K, March CJ, Park LS, Martin U, Mochizuki DY, Boswell HS, Burgess GS, Cosman $\mathrm{D}$, Lyman SD: Identification of a ligand for the c-kit proto-oncogene. Cell 1990, 63:167-174

30. Maeda H, Yamagata A, Nishikawa S, Yoshinaga K, Kobayashi S, Nishi K, Nishikawa S: Requirement of c-kit for development of intestinal pacemaker system. Development 1992, 116:369-375

31. Hosoda K, Hammer RE, Richardson JA, Baynash AG, Cheung JC Giaid A, Yanagisawa M: Targeted and natural (piebald-lethal) mutations of endothelin-B receptor gene produce megacolon associated with spotted coat color in mice. Cell 1994, 79:1267-1276

32. Matsushima $Y$, Shinkai $Y$, Kobayashi $Y$, Sakamoto M, Kunieda $T$, Tachibana M: A mouse model of Waardenburg syndrome type 4 with a new spontaneous mutation of the endothelin-B receptor gene. Mamm Genome 2002, 13:30-35

33. Baynash AG, Hosoda K, Giaid A, Richardson JA, Emoto N, Hammer RE, Yanagisawa M: Interaction of endothelin-3 with endothelin-B receptor is essential for development of epidermal melanocytes and enteric neurons. Cell 1994, 79:1277-1285

34. Saur D, Vanderwinden JM, Seidler B, Schmid RM, De Laet MH, Allescher HD: Single-nucleotide promoter polymorphism alters transcription of neuronal nitric oxide synthase exon 1c in infantile hypertrophic pyloric stenosis. Proc Natl Acad Sci USA 2004, 101:1662-1667

35. Kelley TJ, Cotton CU, Drumm ML: In vivo activation of CFTR-dependent chloride transport in murine airway epithelium by CNP. Am J Physiol 1997, 273:L1065-L1072 